Вип. 1, 2019

УДК 629.313.33

П. А. Болкот

Національний університет “Львівська політехніка", кафедра електромехатроніки та комп'ютеризованих електромеханічних систем, Petro.A.Bolkot@lpnu.ua

М. В. Хай

Національний університет “Львівська політехніка", кафедра електромехатроніки та комп’ютеризованих електромеханічних систем, mxaishk@gmail.com

Б. М. Харчишин Національний університет “Львівська політехніка”, кафедра електромехатроніки та комп'ютеризованих електромеханічних систем, Bohdan.M.Kharchyshyn@lpnu.ua

\title{
МАТЕМАТИЧНА МОДЕЛЬ ВИЗНАЧЕННЯ \\ МАГНІТНИХ ПРОВІДНОСТЕЙ ДАВАЧІВ КУТА IЗ ТРАНСВЕРСНОЮ МАГНІТНОЮ СИСТЕМОЮ
}

https://doi.org/10.23939/sepes2019.01.001

(C) Болкот П. А., Хай М. В., Харчишин Б. М., 2019

Описано математичну модель визначення магнітних провідностей індукційних давачів обмеженого кута повороту з урахуванням лінійних та кутових розмірів специфічної конструкції його магнітопроводу, технологічних похибок виготовлення та монтажу, що симулюсться неспіввісністю розташування статора та ротора. Модель побудовано із використанням допущення про відсутність потоків розсіяння, зумовленого конструктивним розташуванням сигнальних обмоток та обмотки збудження. Однак основний магнітний потік розділено на дві частини - залежну від кутового положення ротора та незалежну, тобто корисний потік, який визначає інформаційну складову сигналу та фонову. Корисний потік визначається величиною корисної провідності, що враховує випучування магнітного потоку. Корисні провідності подано у вигляді таблиці аналітичних виразів, які визначаються однотипно як провідності між двома плоскими поверхнями, розташованими під кутом, із наведенням окремо меж інтегрування.

Модель дас змогу розділяти діапазон кута повороту давача на піддіапазони, кількість яких залежить від кількості зубців магнітопроводу статора.

Математичну модель побудовано для лінійного давача, результати узагальнено на давач обмеженого кута повороту. Модель дає змогу пояснити природу систематичної похибки вихідної характеристики давачів та здійснювати заходи щодо запобігання їй.

Використовуючи принципи побудови математичної моделі, ми практично визначили магнітні провідності для чотиризубцевого давача кута типу ДУ60 з урахуванням штучно 
введеної похибки неспіввісності статора та ротора. Результати наведено у вигляді графіків залежності корисних провідностей зубців від кута повороту.

Зроблено висновок про можливість подальшого використання пропонованої математичної моделі, побудованої на основі методу імовірних шляхів потоків, для визначення природи систематичної похибки вихідної характеристики давачів кута та здійснення запобіжних заходів задля ії уникнення.

Ключові слова: індукційний давач кута; обмежсний кут повороту; трансверсна магнітна система; математична модель; магнітна провідність; корисний магнітний потік; інформаційна складова сигналу; обмотка збудження; сигнальна обмотка.

\section{Вступ}

Давач кута індукційного типу дугостаторної конструкції (ДК) складається із двох механічно не зв'язаних між собою конструктивних частин - якоря та статора (рис. 1), основними елементами яких $є$ магнітопроводи спеціальної конфігурації, виконані із магнітом'якого фериту, що утворюють магнітну систему трансверсного типу (рис. 2) [1-3].
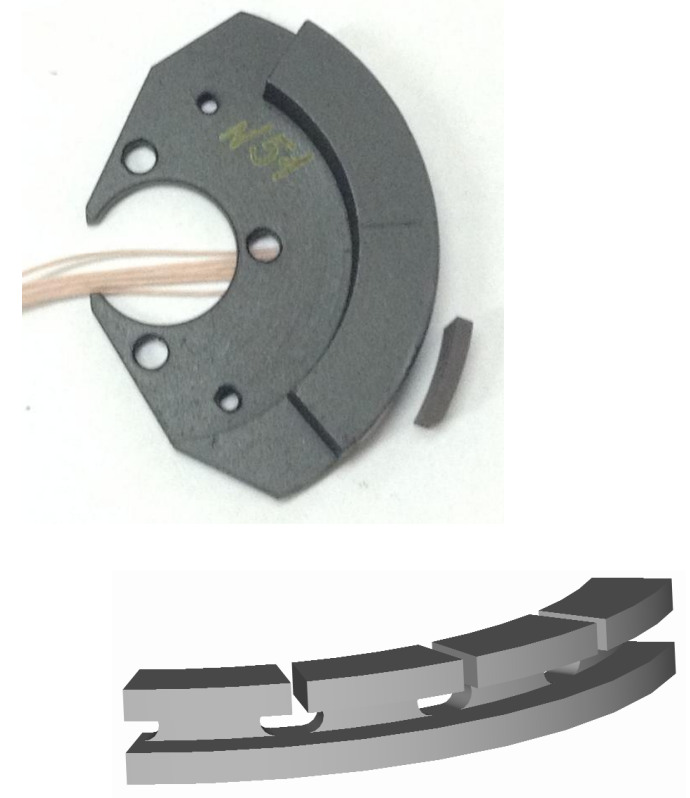

Pис. 2. Магнітопровід статора ДУбО
Рис. 1. Зовнішній вигляд давача

кута трансверсного типу

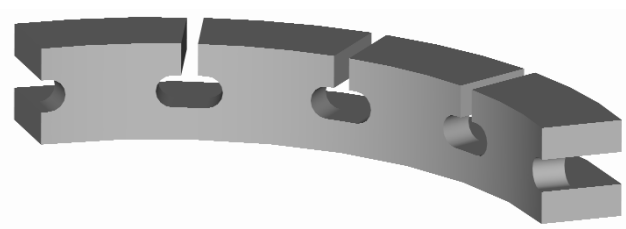

Аналіз останніх досліджень і постановка задачі

Експериментальні дослідження вихідної характеристики давачів кута [3] вказують на наявність у коді вихідного сигналу систематичної похибки, яку можна усунути математично, цифровим обробленням або усуненням її причини [4]. Імовірною причиною систематичної похибки ДК $є$ технологічні похибки його виготовлення та монтажу. Для оцінки допустимих значень технологічних похибок треба визначити їх кількісний вплив на значення систематичної похибки, що дасть змогу здійснити математична модель визначення магнітних провідностей ДК 3 урахуванням технологічних відхилень виготовлення.

\section{Завдання дослідження}

Завдання цього дослідження - створити математичну модель для визначення робочих магнітних провідностей та провідностей розсіяння магнітних потоків давача кута трансверсного типу задля подальшого їх використання із застосуванням відповідних методик [5] в оптимізаційних розрахунках та дослідженнях впливу технологічних похибок виготовлення та монтажу на метрологічні показники. 


\section{Об’скт досліджень}

Об'єктом досліджень у цій статті є магнітна система давачів кута трансверсного типу, зокрема давача кута ДУ60, розробленого в СКБ ЕМС Львівської політехніки (рис. 1).

\section{Виклад основного матеріалу}

Зважаючи на конструктивні особливості давача кута, потоки розсіяння є нехтовно малими, тому вважатимемо всі магнітні провідності корисними, тобто такими, що потік, який перетікає по них, повністю зчеплений із сигнальними обмотками давача. Відсутність потоків розсіяння дає змогу систематизувати провідності магнітної системи давачів обмеженого кута повороту, розділивши їх на дві групи: незалежні та залежні від кута повороту $\gamma$.

Провідності першої групи, приведені до одиниці довжини розточки зубця ДК (позначатимемо малими літерами $\lambda$ ), показано на радіальному поперечному перерізі статора за відсутності якоря - ротора (рис. 3).

Для визначення цих та інших провідностей скористаємося методом імовірних шляхів потоку для геометричних розмірів, зображених на рис. 1, ураховуючи, що довжина силової лінії зі зміною радіальної координати змінюється лінійно, тому еквівалентне значення довжини силової лінії визначається як середнє між крайніми

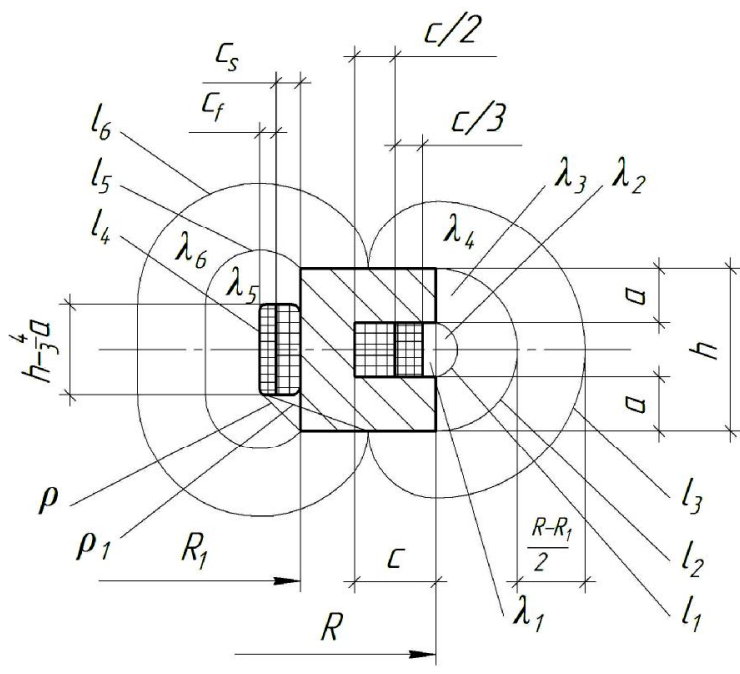

Рис. 3. Радіальний поперечний переріз статора ДК

$$
\lambda_{1}=\mu_{0} \frac{c}{6(h-2 a)} .
$$

Аналогічно еквівалентне значення площі перетину імовірного шляху потоку знаходимо як середнє між найбільшим та найменшим

$$
\begin{gathered}
\lambda_{2}=\mu_{0} \frac{\delta}{h-2 a+l_{1}}, \\
\text { де } l_{1}=\operatorname{arctg}\left(\frac{h / 2-a}{\frac{\delta^{2}+(h / 2-a)^{2}}{2 \delta}-\delta}\right) \cdot \frac{\delta^{2}+(h / 2-a)^{2}}{\delta} \approx 2 \sqrt{\delta^{2}+(h / 2-a)^{2}}, \quad \text { як довжина дуги } 3
\end{gathered}
$$

величиною стрілки $\delta$, що дорівнює величині немагнітного проміжку між статором та ротором;

$$
\lambda_{3}=\mu_{0} \frac{h-2 \delta}{l_{1}+l_{2}},
$$

де $l_{2}=\pi \cdot h / 2$;

$$
\lambda_{4}=\mu_{0} \frac{R-R_{1}}{l_{2}+l_{3}}
$$

де $l_{3}=\pi \cdot\left(h / 2+R-R_{1}\right)$;

$$
\lambda_{5}=\mu_{0} \frac{2 \rho}{l_{4}+l_{5}},
$$


де $\rho=\sqrt{\left(c_{s}+c_{f} / 2\right)^{2}+(2 a / 3)^{2}}-$ приведений до одиниці довжини розточки параметр, еквівалентний до площі трубки провідності $\lambda_{5} ; c_{s}=(h-2 a) c /(2 h-8 a / 3), c_{f}=(h-2 a) c /(3 h-4 a)-$ лінійні розміри, що враховують зміну конфігурації перетину обмоток ДК (рис. 3); $l_{4}=2 \rho+h / 2-2 a / 3, l_{5}=2\left(\pi-\operatorname{arctg} \frac{2 a / 3}{c_{s}+c_{f} / 2}\right) \rho+h-4 a / 3-$ довжини меж трубки провідності $\lambda_{5}$ ( рис. 3);

$$
\lambda_{6}=\mu_{0} \frac{2\left(\rho_{1}-\rho\right)}{l_{5}+l_{6}}
$$

де $\rho_{1}=\sqrt{c_{s}+c_{f}+\left(R-R_{1}\right)^{2}+(2 a / 3)^{2}}$ - приведений до одиниці довжини розточки параметр, еквівалентний до площі трубки провідності $\lambda_{6}$;

$l_{6}=2\left(\pi-\arcsin \frac{2 a / 3}{\rho_{1}}\right) \rho_{1}+h-4 a / 3-$ довжина зовнішньої межі трубки провідності $\lambda_{6}$.

Для урахування крайових ефектів у моделі потрібно оцінювати також провідності по краях зубців $\lambda_{7 k}$ та $\lambda_{8 k}$ (рис. 4)

та аналогічно (4)

$$
\lambda_{7 k}=\frac{\mu_{0}}{\pi} \ln \frac{1}{1-2 a / h}
$$

$$
\lambda_{8 k}=\mu_{0} \cdot \frac{R-R_{1}}{\pi \cdot h / 2+l_{7}}
$$

де $l_{7}=\pi\left(h / 2-R-R_{1}\right)$ - довжина зовнішньої межі трубки провідності $\lambda_{8}$.

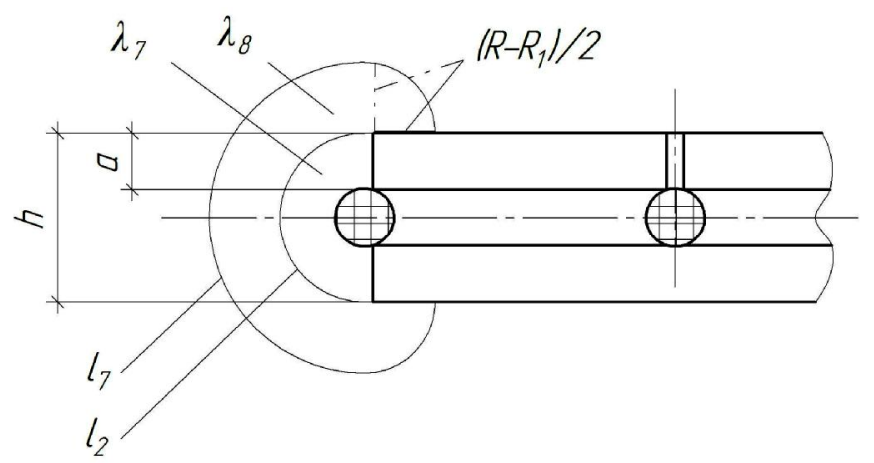

Рис. 4. Лінійна розгортка розточки статора ДК з крайніми провідностями

Отже, сумарна провідність кожного із $n$ зубців ДК за відсутності якоря $\lambda_{i}=\sum_{j=1}^{6} \lambda_{j i}$ для зубців із номером $i=1 \ldots n-2$ та $\lambda_{i}=\sum_{j=1}^{8} \lambda_{j i}$ для зубців $i=0, i=n-1$, де $j=1 \ldots 8-$ номер відповідної магнітної провідності.

За наявності ротора (рис. 5) провідності $\lambda_{3}$ та $\lambda_{4}$ згідно із запропонованою моделлю перетворюються на $\lambda_{b}$ та $\Lambda$ - корисні провідності між ротором та статором. Якщо малі літери $\lambda$ 
досі й надалі означають приведені значення провідності на одиницю довжини зубця, то великі $\Lambda$ означатимуть абсолютні величини, розмірність яких Гн.

Базова корисна бокова провідність відповідно до геометричних розмірів на рис. 5 визначається залежністю

$$
\lambda_{b}=\mu_{0} \cdot \frac{b_{r}+\frac{R-R_{1}}{2}}{\sqrt{\delta^{2}+\left(\frac{h_{r}-h}{2}\right)^{2}}+\frac{\pi}{2} b_{r}+\sqrt{\left(\frac{R-R_{1}}{2}+\delta\right)^{2}+\left(\frac{h_{r}-h}{2}+b_{r}\right)^{2}}} .
$$

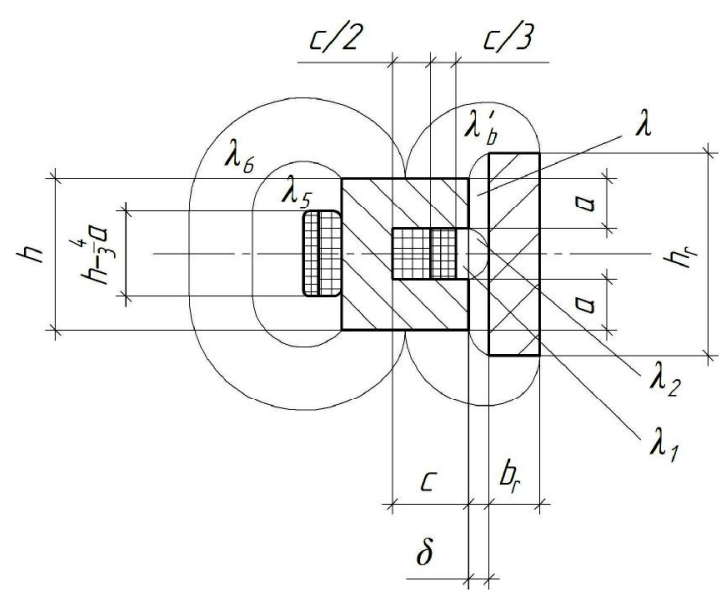

Рис. 5. Радіальний поперечний переріз ДК з ротором

Наголосимо на допущеннях, які використано під час виконаного вище та подальшого моделювання:

1. Вважаємо, що математична модель однаково достовірна для будь-якого діаметра давача кута, зокрема $R=\infty$, а це дає змогу здійснювати моделювання для лінійного давача і застосовувати його до колового. Тому переріз трубки магнітного потоку вважаємо сталим незалежно від радіальної відстані.

2. Провідність між бічними поверхнями якоря та зубцями ігнорується як порівняно мала. Її можна враховувати еквівалентним розрахунковим збільшенням ширини дуги якоря.

3. Вважаємо, що всі магнітні провідності приведені до одиниці довжини дуги розточки зубця (тобто радіуса $R$ ), хоча насправді провідності $\lambda_{5}$ та $\lambda_{6}$ приведені до одиниці довжини дуги дещо іншого радіуса.

4. Бокова провідність $\lambda_{b}$ не враховує технологічної похибки неспіввісності статора та ротора під час виготовлення чи монтування ДК, оскільки вплив іiі на цю провідність занадто малий. Тому вважатимемо іiї сталою незалежно від кутового положення ротора.

Для визначення корисної магнітної провідності робочого немагнітного проміжку, тобто такої, що визначає інформаційну складову вихідного сигналу сигнальних обмоток, необхідно робочий діапазон кутів $\gamma$ розділити на $m=3+2(n-3)$ частин (для $n \geq 3)$ з номером $s=0 \ldots m-1$ (табл. 1 ).

Для прикладу далі розглянуто корисні провідності для чотиризубцевого давача кута ДУ60 3 урахуванням можливості моделювання неспіввісності статора та ротора.

Для визначення цих провідностей скористаємося допущенням про можливість заміни дугового давача на лінійний, що дає змогу вивести аналітичні формули провідності для двох плоских поверхонь, розташованих під кутом, із межами інтегрування $r_{1}$ та $r_{2}$ (рис. 6,7 ). 


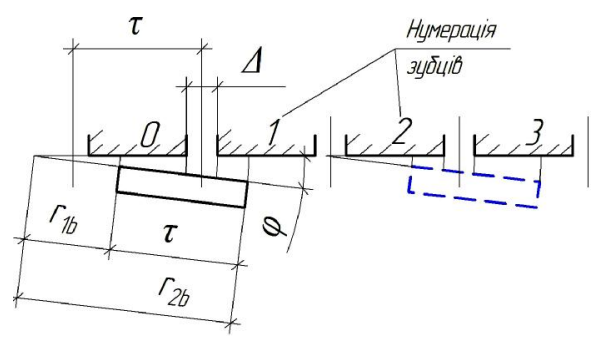

Рис. 6. До визначення базових значень меж інтегрування $r_{1 b}$ та $r_{2 b}$
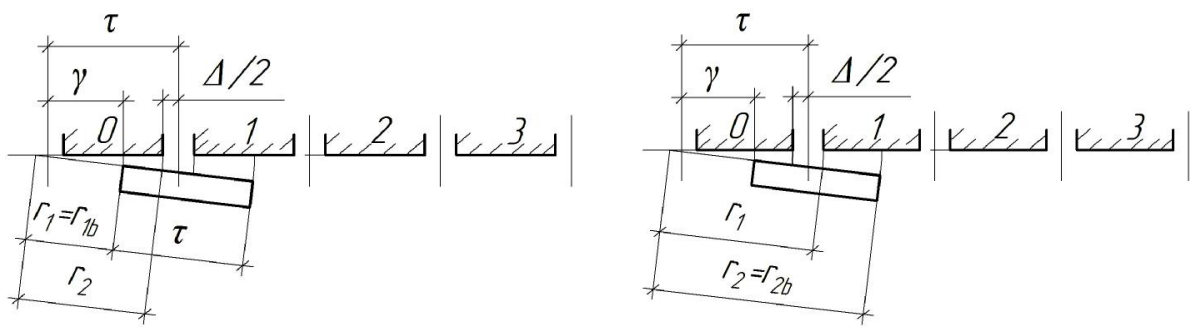

Рис. 7. До визначення провідностей нульового діапазону (нульового та першого зубиів)

Тоді магнітні провідності

$$
\Lambda_{s i}(\gamma)=\mu_{0} \frac{a+\left(h_{r}-h\right) / 2}{\varphi} \int_{r_{1}}^{r_{2}} \frac{1}{\delta+\varphi r} d r
$$

для різних $s$ та $i$ відрізнятимуться лише значеннями меж інтегрування $r_{1}$ та $r_{2}$ (табл. 2) за таких базових значень

$$
r_{1 b}=\frac{\delta}{\varphi} \quad \text { та } \quad r_{2 b}=r_{1 b}+\tau
$$

Корисні провідності зубців із урахуванням провідностей випучування з бокових поверхонь для кожного діапазону кута

\begin{tabular}{|c|c|c|c|c|c|}
\hline $\mathrm{s}$ & Робочий кут $\gamma \quad \backslash \Lambda_{i}$ & $\Lambda_{0}$ & $\Lambda_{1}$ & $\Lambda_{2}$ & $\ldots$ \\
\hline 0 & {$\left[\frac{\Delta}{2} ; \tau-\frac{\Delta}{2}\right]$} & $\Lambda_{00}(\gamma)+\Lambda_{00 b}(\gamma)$ & $\Lambda_{01}(\gamma)+\Lambda_{01 b}(\gamma)$ & 0 & 0 \\
\hline 1 & {$\left[\tau-\frac{\Delta}{2} ; \tau+\frac{\Delta}{2}[\right.$} & 0 & $\Lambda_{11}(\gamma)+\Lambda_{11 b}(\gamma)$ & 0 & 0 \\
\hline 2 & {$\left[\tau+\frac{\Delta}{2} ; 2 \tau-\frac{\Delta}{2}\right]$} & $\Lambda_{21}(\gamma)+\Lambda_{21 b}(\gamma)$ & $\Lambda_{22}(\gamma)+\Lambda_{22 b}(\gamma)$ & 0 \\
\hline 3 & {$\left[2 \tau-\frac{\Delta}{2} ; 2 \tau+\frac{\Delta}{2}[\right.$} & 0 & $\Lambda_{31}(\gamma)+\Lambda_{23 b}(\gamma)$ & 0 \\
\hline$\ldots$ & $\ldots$ & 0 & 0 & $\ldots$ & $\ldots$ \\
\hline $\mathrm{s}$ & {$\left[s \cdot \tau+\frac{\Delta}{2} ;(s+1) \tau-\frac{\Delta}{2}\right]$} & 0 & 0 & 0 & 0 \\
\hline $\mathrm{s}+1$ & {$\left[(s+1) \tau-\frac{\Delta}{2} ;(s+1) \tau+\frac{\Delta}{2}[\right.$} & 0 & 0 & 0 & 0 \\
\hline$\ldots$ & {$\left[(m-1) \cdot \tau+\frac{\Delta}{2} ;(m) \tau-\frac{\Delta}{2}\right]$} & 0 & & & 0 \\
\hline$m-1$ & {$[(m-1)$} & 0 & & 0 \\
\hline
\end{tabular}


Продовження табл. 1

\begin{tabular}{|c|c|c|c|c|c|c|}
\hline $\mathrm{s}$ & $\ldots$ & $\Lambda_{i}$ & $\Lambda_{i+1}$ & $\ldots$ & $\Lambda_{n-2}$ & $\Lambda_{n-1}$ \\
\hline 0 & 0 & 0 & 0 & 0 & 0 & 0 \\
\hline 1 & 0 & & 0 & 0 & 0 & 0 \\
\hline 2 & 0 & 0 & 0 & 0 & 0 & 0 \\
\hline 3 & 0 & 0 & 0 & 0 & 0 & 0 \\
\hline$\ldots$ & $\ldots$ & $\ldots$ & $\Lambda_{s i(i+1)}(\gamma)+\Lambda_{s(i+1) b}(\gamma)$ & 0 & 0 & 0 \\
\hline$s$ & 0 & $\Lambda_{s i}(\gamma)+\Lambda_{s i b}(\gamma)$ & $\Lambda_{(s+1)(i+1)}(\gamma)+\Lambda_{(s+1)(i+1) b}(\gamma)$ & 0 & 0 & 0 \\
\hline$s+1$ & 0 & 0 & $\ldots$ & $\cdots$ & $\ldots$ & 0 \\
\hline$\ldots$ & 0 & 0 & 0 & 0 & $\begin{array}{c}\Lambda_{(m-1)(n-2)}(\gamma)+ \\
+\Lambda_{(m-1)(n-2) b}(\gamma)\end{array}$ & $\begin{array}{c}\Lambda_{(m-1)(n-1)}(\gamma)+ \\
+\Lambda_{(m-1)(n-1) b}(\gamma)\end{array}$ \\
\hline$m-1$ & & 0 & & & & \\
\hline
\end{tabular}

Таблиия 2

Значення меж інтегрування $r_{1}$ та $r_{2}$ для визначення корисних провідностей зубців для кожного діапазону кута

\begin{tabular}{|c|c|c|c|c|}
\hline $\mathrm{s}$ & $i=0$ & $i=1$ & $i=2$ & $i=3$ \\
\hline 0 & $\begin{array}{c}r_{1}=r_{1 b} \\
r_{2}=r_{1 b}-\gamma-\frac{\Delta}{2}+\tau\end{array}$ & $\begin{array}{c}r_{1}=r_{2 b}-\gamma+\frac{\Delta}{2} \\
r_{2}=r_{2 b}\end{array}$ & 0 & 0 \\
\hline 1 & 0 & $\begin{array}{l}r_{1}=r_{1 b}-\gamma+\tau+\frac{\Delta}{2} \\
r_{2}=r_{1 b}-\gamma+2 \tau-\frac{\Delta}{2}\end{array}$ & 0 & 0 \\
\hline 2 & 0 & $\begin{array}{c}r_{1}=r_{1 b} \\
r_{2}=r_{1 b}-\gamma-\frac{\Delta}{2}+2 \tau\end{array}$ & $\begin{array}{c}r_{1}=r_{1 b}-\gamma+\frac{\Delta}{2}+2 \tau \\
r_{2}=r_{2 b}\end{array}$ & 0 \\
\hline 3 & 0 & 0 & $\begin{array}{l}r_{1}=r_{1 b}-\gamma+2 \tau+\frac{\Delta}{2} \\
r_{2}=r_{1 b}-\gamma+3 \tau-\frac{\Delta}{2}\end{array}$ & 0 \\
\hline 4 & 0 & 0 & $\begin{array}{c}r_{1}=r_{1 b} \\
r_{2}=r_{1 b}-\gamma-\frac{\Delta}{2}+3 \tau\end{array}$ & $\begin{array}{c}r_{1}=r_{1 b}-\gamma+\frac{\Delta}{2}+3 \tau \\
r_{2}=r_{2 b}\end{array}$ \\
\hline
\end{tabular}

Використовуючи викладені вище принципи побудови математичної моделі визначення магнітних провідностей для чотиризубцевого давача кута, ми встановили залежності корисних провідностей зубців $\Lambda_{i}(\gamma)$ від кута повороту $\gamma$ (рис. 8) з урахуванням штучно введеної похибки неспіввісності статора та ротора, еквівалентної куту $\varphi$. 

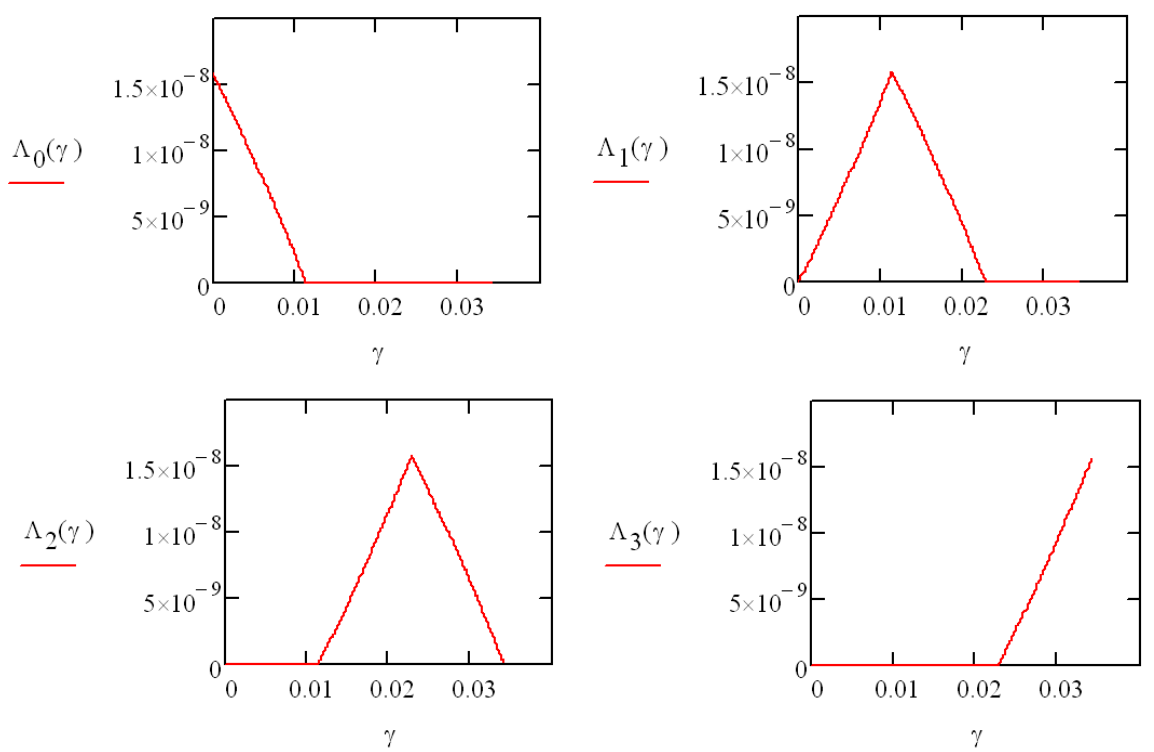

Рис. 8. Залежності корисних магнітних провідностей $\Lambda_{i}(\gamma)$ для кожного зубия ДК

\section{Висновки}

Отже, створена математична модель, побудована на основі методу імовірних шляхів потоків, дає змогу знаходити провідності, які визначають фонову та інформаційну складові вихідного сигналу багатозубцевих індукційних давачів обмеженого кута повороту із трансверсною магнітною системою. Модель дає можливість врахувати технологічні похибки виготовлення та монтажу, що дозволить у подальших дослідженнях визначити природу систематичної похибки вихідної характеристики ДК та вжити заходів задля іï уникнення.

\section{Список використаних джерел}

1. Завгородній В. Д. Квантово-механічна модель давачів кута індукційного типу (Частина 6. Безконтактні давачі обмеженого кута повороту) / В. Д. Завгородній // Електротехніка і електромеханіка. 2005. № 4. C. $45-50$.

2. Бойко А. С. Основи проектного розрахунку давачів обмеженого кута повороту з трансверсною магнітною системою / А. С. Бойко, В. Д. Завгородній // Електротехніка і електромеханіка. 2008, № 5. С. 10-15.

3. Kharchyshyn B.M. Functional testing of angle-data transmitters of the limited rotation angle / B. M. Kharchyshyn, M.V. Khai, P. A. Bolkot // Bulletin of NTU "KhPI". Series: "Electric machines and electromechanical energy conversion". - Kharkiv : NTU "KhPI", 2017. No. 1 (1123). P. 48-51. Bibliogr.: 3.

4. Болкот П. А. Давач обмеженого кута повороту / П.А.Болкот, В.І.Грабчак, М. В.Хай, Б. М. Харчишин // Патент України на корисну модель № 135951 від 25.07.2019 р. Бюл. № 14.

5. Харчишин Б. М. Спосіб покращення метрологічних характеристик давачів обмеженого кута повороту / Б. М. Харчишин // Електроенергетичні та електромеханічні системи. Вісник Національного університету “Львівська політехніка". 2010. Вип. 671. С. 113-117.

\section{References}

1. Zavgorodnij V. D. Kvantovo-mexanichna model davachiv kuta indukcijnogo typu (Chastyna 6. Bezkontaktni davachi obmezhenogo kuta povorotu) / V. D. Zavgorodnij // Elektrotexnika i elektromexanika. 2005. No. 4. S. 45-50.

2. Bojko A. S. Osnovy proektnogo rozraxunku davachiv obmezhenogo kuta povorotu z transversnoyu magnitnoyu systemoyu / A. S. Bojko, V. D. Zavgorodnij // Elektrotexnika i elektromexanika. 2008, No. 5. S.10-15.

3. Kharchyshyn B. M. Functional testing of angle-data transmitters of the limited rotation angle / B. M. Kharchyshyn, M.V. Khai, P. A. Bolkot // Bulletin of NTU "KhPI". Series: "Electric machines and electromechanical energy conversion". Kharkiv : NTU "KhPI", 2017. No. 1 (1123). P. 48-51. Bibliogr.: 3.

4. Bolkot P. A. Davach obmezhenogo kuta povorotu / P. A. Bolkot, V. I. Grabchak, M. V. Xaj, B. M. Xarchy`shy`n // Patent Ukrayiny`na kory `snu model’ № 135951 vid 25.07.2019 r. Byul. No. 14. 
Математична модель визначення магнітних провідностей давачів кута ...

5. Xarchyshyn B. M. Sposib pokrashhennya metrologichnyx xarakterystyk davachiv obmezhenogo kuta povorotu / B. M. Xarchyshyn // Elektroenergetychni ta elektromexanichni systemy. Visnyk Nacionalnogo universy 'tetu "L vivs ka politexnika", 2010. Vyp. 671. P. 113-117.

P. A. Bolkot

Lviv Polytechnic National University, Department of Electromechatronics and Computerized Electromechanical Systems, Petro.A.Bolkot@1pnu.ua

M. V. Khaj
Lviv Polytechnic National University,
Department of Electromechatronics and Computerized Electromechanical Systems,
mxaishk@gmail.com

B. M. Kharchyshyn

Lviv Polytechnic National University, Department of Electromechatronics and Computerized Electromechanical Systems, Bohdan.M.Kharchyshyn@lpnu.ua

\section{MATHEMATICAL MODEL OF DETERMINATION OF MAGNETIC CONDUCTANCE OF ANGLE-DATA TRANSMITTER WITH TRANSVERSE MAGNETIC SYSTEM}

(C) Bolkot P. A., Khaj M. V., Kharchyshyn B. M., 2019

The mathematical model for defining the magnetic conductivity of inductive transmitters of the limited rotation angle is described; both linear and angular dimensions of magnetic core's specific construction and technological errors of production and installation which is simulated by the misalignment of the stator and the rotor location was taken into consideration. The model is constructed assuming that there are no scattering streams due to the structural arrangement of the signal and the excitation windings. However, the main magnetic flow is divided into two parts: a part that is dependent on the rotor's angular position and an independent one, meaning a useful flow that determines the information component of the signal and the background. The useful flow is determined by the magnitude of the useful conductivity taking into account the emission of the magnetic flow. Useful conductivity is presented in the form of a table of analytical expressions defined uniformly as the conductivity between two flat surfaces at an angle; the integration bounds are provided separately.

The model allows breaking the range of the angle of the angle-data transmitter into subranges, which number depend on the number of teeth in the stator core.

The mathematical model is built for a linear transmitter and the results are summarized for transmitters of the limited rotation angle. The model allows to explain the nature of the systematic error of the original transmitters' characteristics and take measures to prevent them.

By integrating the principles of constructing the mathematical model, the practical determination of magnetic conductivity for the angle-data transmitter with four teeth (of type ДУ 60) has been conducted; the artificially introduced error of the stator and rotor mismatch has been taken into account. The results are presented in the form of dependency graphs of the useful conductivity of the teeth on the rotation angle.

The conclusion has been drawn about the possibility of further use of the proposed mathematical model based on the method of probable flow paths for defining the nature of the systematic error of the original transmitters' characteristics and taking measures to prevent them.

Key words: inductive angle-data transmitter; limited rotation angle; transverse magnetic system; mathematical model; magnetic conductance; the useful flow; the information component of the signal; the excitation winding; the signal winding. 